Borneo Journal of Sciences \& Technology, Volume (3), Issue (1), Pages: 29-33

DOI: http://doi.org/10.3570/bjost.2021.3.1-05

e-ISSN: 2672-7439

(C) 2018, UCTS Publisher.

Submitted: $02^{\text {nd }}$ Jun 2020

Accepted: $11^{\text {th }}$ November 2020

Published: $31^{\text {st }}$ January 2021

\title{
Synthesis of Nano Zero Valent Iron, Treatment of Wastewater with Fenton Process Assisted by Ultrasound and its Impact on the Environment: A Review
}

\author{
Bryan Wong Lee Peng, Augustine Chioma Affam, and Wong Chee Chung \\ School of Engineering and Technology, University College of Technology Sarawak (UCTS), \\ 96000 Sibu, Sarawak, Malaysia
}

\begin{abstract}
Usage of metallic or bimetallic nano materials for water remediation has been practiced greatly in recent years. Among all the nano materials available, nano zero valent iron (nZVI) is chosen as the most regularly used and research nano material due to its simplicity to synthesize and its efficacy in removing non-biodegradable pollutants in recalcitrant wastewater which are difficult to be removed through Fenton process. The objective of the study is to review the synthesis method of nZVI, namely chemical reduction method and green synthesis method, determining the effectiveness of coupling nZVI and ultrasound for wastewater treatment as well as the possible environmental effects of nZVI to the ecosystem. Chemical reduction method refers to the reduction with sodium borohydride with the equation $\mathrm{Fe}\left(\mathrm{H}_{2} \mathrm{O}\right)_{6}^{3+}+3 \mathrm{BH}_{4}^{-}+3 \mathrm{H}_{2} \mathrm{O} \rightarrow \mathrm{Fe}^{0} \Downarrow+3 \mathrm{~B}(\mathrm{OH})_{3}+10.5 \mathrm{H}_{2}$ while green synthesis method is done through bio-synthesizing of nanoparticles via plant mixing with $\mathrm{Fe}^{2+}$ solutions where the ions will reduce to nZVI with the presence of polyphenols. These nZVI produced will then be used for recalcitrant wastewater treatment through Fenton process, where organic pollutants are oxidized by hydroxyl radicals that are produced by the reaction of iron (II) and hydrogen peroxide. The studies have shown that Sono-Fenton process (An ultrasound assisted Fenton Process) yields drastically better pollutants removal compared to traditional Fenton process. That being said, the research concludes that different wastewater requires very different treatment conditions and parameters in order to achieve the maximum pollutants removal. Therefore, sufficient testing must be done before designing the parameters of Fenton or Sono-Fenton process for a specific wastewater treatment. A significant amount of negative impacts of nZVI towards the environment were found from the studies, including effects on bacteria growth and cell functions, aquatic organisms and also plants due to its toxicity. Nevertheless, it has to be noted that the toxicity level of nZVI is known to be the lowest when compared to other zero valent metals and therefore stays as the better options to be studied and used for wastewater treatment in the future.
\end{abstract}

Keywords: Nano zero valent iron, Ultrasonic processing, Palm oil mill effluent, Water remediation, Environmental impact

\section{INTRODUCTION}

Using technology of nano particles for soil or water remediation has become a widespread practice in recent years due to their recognized effectiveness in the field [1]. Among all the nano particles involved, nano zero valent iron is being studied and tested the most due to its simplicity of synthesizing and its effectiveness in removing a wide range of pollutants including recalcitrant pollutants $[2,3]$. Two methods of nZVI synthesis will be studied, with the most common method being chemical reduction as well as the latest developing method being green synthesis which focuses more on eco-friendly production. Studies has also shown that introduction of ultrasound during Fenton process enhances the effectiveness in treatment of recalcitrant organics. Studies have shown that the introduction of high intensity ultrasound over a long time during the treatment using nZVI enhances the production of $\mathrm{Fe}^{2+}$ ions which promotes the removal of COD in recalcitrant wastewater [2]. Unfortunately, the use of nZVI for water remediation comes with its risk of secondary pollution for the environment, mainly due to the insufficient research regarding their toxicity [4]. The aim of this research is to study the synthesis methods of nZVI, specifically chemical reduction method and green synthesis method, determining the effectiveness of coupling nZVI and ultrasound for wastewater treatment as well as the environmental effects of nZVI to the ecosystem. 


\section{SYNTHESIS METHODS}

\section{Chemical Reduction Method with Ultrasound Assist}

A number of methods has been discovered over the years to synthesis and produce nZVI. More conventional method includes physical methods such as grinding, abrasion and lithography [5].

Other than the physical methods, chemical methods were also developed including reduction with sodium borohydride as shown in the chemical equation below [6, 7]:

$\mathrm{Fe}\left(\mathrm{H}_{2} \mathrm{O}\right)_{6}^{3+}+3 \mathrm{BH}_{4}^{-}+3 \mathrm{H}_{2} \mathrm{O} \rightarrow \mathrm{Fe}^{0} \downarrow+3 \mathrm{~B}(\mathrm{OH})_{3}+10.5 \mathrm{H}_{2}$

The production includes dissolving of $2.5 \mathrm{~g}$ of sodium borohydride in $60 \mathrm{ml}$ of deoxygenated deionized (DI) water. The mixture is pumped at the $20 \mathrm{ml} / \mathrm{min}$ rate into a flask containing $2.5 \mathrm{~g}$ ferric chloride which is dissolved in $60 \mathrm{ml}$ of DI water stirring at a fixed speed of 250 rotation per minute (rpm) and will only stop 20 minutes after the injection of sodium borohydride finished to ensure thorough reaction. The whole system is kept in a water bath at $25^{\circ} \mathrm{C}$. Particles produced from the reaction were then filtered and washed for three times with a mixture of $10 \%$ ethanol and $90 \%$ DI water before dried and stored [6].

This method can be enhanced with the inclusion of ultrasound, where its application results in smaller and more consistent grains of iron sizes at approximately $10 \mathrm{~nm}$ which is smaller than their normal sizes at $34 \mathrm{~nm}$ which promotes a greater specific surface area $[8,9]$. Introduction of ultrasound turns the reaction into the equation as follows:

$4 \mathrm{Fe}_{\text {(aq) }}^{2+}+\mathrm{BH}_{4(\mathrm{aq})}^{-}+3 \mathrm{H}_{2} \mathrm{O} \rightarrow 3 \mathrm{Fe}^{0} \downarrow+\mathrm{H}_{3} \mathrm{BO}_{3(\text { aq })}+7 \mathrm{H}_{(\text {(aq) }}^{+}$

Other than smaller and more uniform particle size of nZVI, ultrasound also changes the surface morphology of nZVI depending on the frequency and intensity used [9]. The generic shape of nZVI appears to be spherical, but different frequency of ultrasound may result with surface morphology of plate or even needle types which is caused by the acoustic waves that inhibits the growth of $\mathrm{Fe}^{2+}$ [9]. The ultrasonic waves carry acoustic energy that is capable of changing the physical structure of nano particles by restricting the growth of metal iron $[10,11]$.

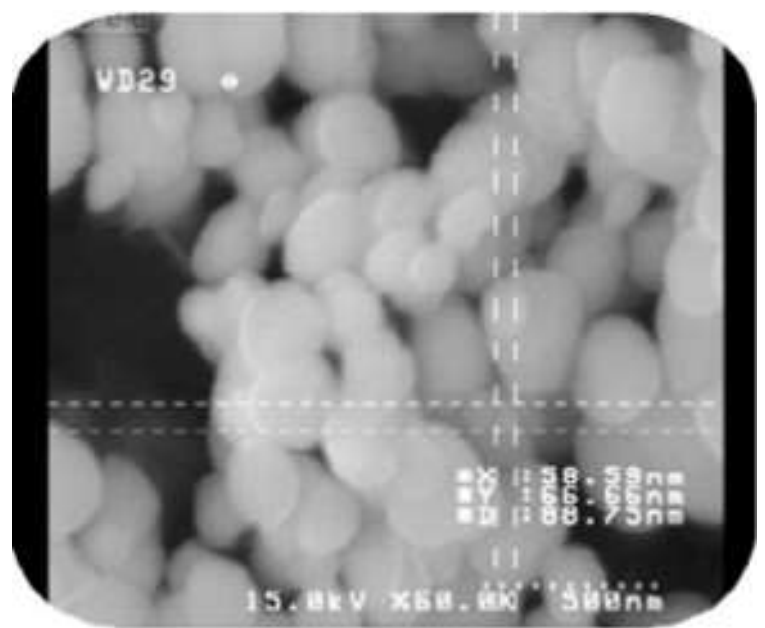

Figure 1: FESEM image of nZVI with Spherical Surface Morphology [9]

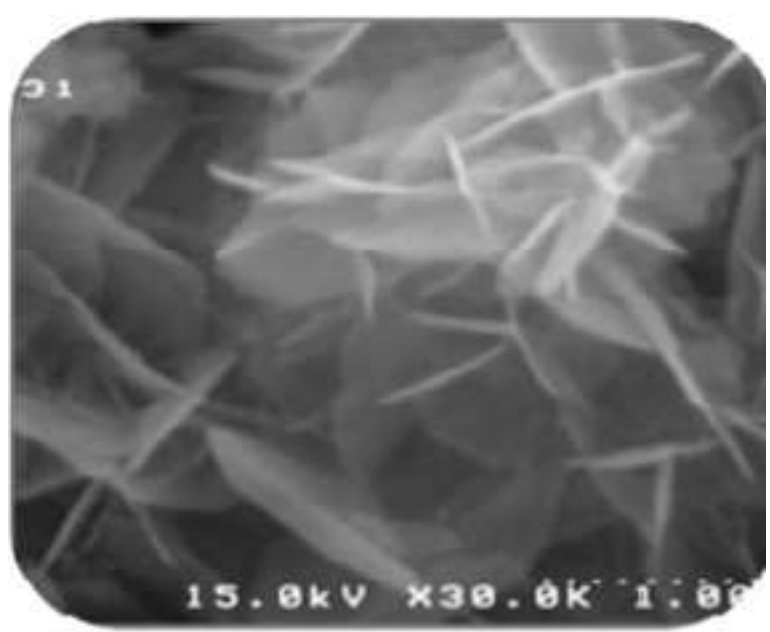

Figure 2: FESEM image of nZVI with Needle Surface Morphology [9]

\section{Green Synthesis}

Green synthesis method is a newly developed method that focuses on being eco-friendly by bio-synthesizing nanoparticles. It is environmental friendly and cheap, since it can be done at large scales without the need of any costly power consumption generator or energy [12, 13]. A polyphenolic solution is prepared by heating of plant extracts such as green tea, black tea, grapes and so on in water with the temperature in close proximity to the boiling point. Next, the polyphenolic extract prepared is mixed with $\mathrm{Fe}^{2+}$ solution where iron ions will be reduced to nZVI with the presence of polyphenols [14].

Studies has shown that usage of plant extracts for synthesis of nZVI requires shorter durations for metal ions reducing compared to microbes. Depending on the variance of plants used as well as the phytochemical concentration available, nZVI can be synthesized from a few minutes to hours, a much shorter time compared 
to microorganism-based method [4]. Other than that, microbe-mediated synthesis method also requires trained expert and specific conditions to achieve the desired result which leads to higher production cost. Compared to that, green synthesis requires minimal expertise due to its simplicity and with the abundance of plants in nature, making it a much more favoured method [15].

Green synthesis is knowingly appraised as the environmental friendly and cost effective method presently available to produce nZVI, with the main liability being the ruination of plants or plant parts during the process. Fortunately, this problem can be countered with the employment of agro waste such as fruit residues from peels or flesh $[13,16]$.

\section{TREATMENT METHODS}

\section{Fenton Process}

Fenton chemistry was first discovered by H.J.H. Fenton as an alternative method over traditional oxidation process for treatment of recalcitrant organics, with oxidation of organic pollutants via hydroxyl radicals that are produced by the reaction of iron (II) and hydrogen peroxide [17]. In recent studies, coupling of ultrasound with Fenton process has become a well reckoned advanced oxidation processes for recalcitrant wastewater remediation [2].

In a typical Fenton process treatment, source of $\mathrm{Fe}^{2+}$ comes mainly from the reaction of $\mathrm{FeSO}_{4}$ and hydrogen peroxide. The reaction produces hydroxyl radicals $\left(\mathrm{OH}^{\circ}\right)$ which instantly reacts when in contact with organic compounds or contaminants in the wastewater via a few mechanisms including electron transfer, radical combination, hydrogen abstraction or radical addition [18]. The oxidation process transforms organic pollutants into carbon dioxide $\left(\mathrm{CO}_{2}\right)$, water $\left(\mathrm{H}_{2} \mathrm{O}\right)$ and salt [2].

\section{Ultrasound Assisted Fenton Process (Sono-Fenton)}

Effectiveness of Fenton process in water remediation highly relies on two factors which are the rate of production of free radicals, which in this case the hydroxyl radicals $\left(\mathrm{OH}^{\circ}\right)$ and also the frequency of these radicals contacting the molecules of the contaminant [19]. These factors shows that the process alone does not attain phenomenal efficiency in treatment which directly leads to less unideal economical values for operation [19]. The same scenario happens to ultrasonic technology, where treatment of wastewater with ultrasound alone yields a rather low oxidation rate [20].

Fortunately, there are homogenous pollutants oxidations from both of the methods and therefore a better treatment effectiveness can be achieved with the combination of the two, also known as Sono-Fenton process [19]. Plenty of researchers has tested the hypothesis and yielded very affirmative results for the treatment of a wide range of effluents including industrial wastewater, palm oil mill effluent (POME), oily sludge and phenolic aqueous solution $[2,19,21$, 22]. These researches identify a few factors contributing to the enhanced or better results from Sono-Fenton process compared to Fenton process alone.

When ultrasound at high frequencies and intensity is introduced to the solution, nZVI particles were more evenly dispersed throughout the solution which promotes contact and reaction to produce more $\mathrm{Fe}^{2+}$ if compared to Fenton process alone, which directly improves the efficiency of the treatment process in removing pollutants [2]. Other than that, high frequencies of ultrasound also result in higher yield of $\mathrm{OH}^{\circ}$ radicals due to a better rate of reaction in the solution [22].

\section{ENVIRONMENTAL IMPACT}

In spite of the fact that nZVI is proven effective in water remediation, it still poses a risk of harming the environment mainly due to its often neglected toxicity [4]. During a treatment, nZVI may be adsorbed on the bacteria's cell membrane, and at some cases it may even penetrates the membrane wall [23]. Most of the time this scenario will results in malfunctioning of the cell itself, or even death due to blockage of cellular ducts by the nZVI adsorbed on the membrane, causing structural changes, immobility and avert nutrition intake of the bacteria [24].

Besides affecting bacteria's growth and cell functions, usage of nZVI also poses negative impacts to aquatic organisms. Studies have shown that the introduction of nZVI during treatment reduces the overall oxygen level of the environment being treated [25]. Reduction of oxygen level is mainly caused by the oxidation process of nZVI which uses oxygen [25]. This directly impacts the organisms which worsen their mortality and reproductions due to deficiency of oxygen $[25,26]$.

Effects of nZVI towards the environment does not stop at aquatic level itself. Studies have shown that toxicity of nZVI also affects plants in some ways [2729]. nZVI tend to accumulate and deposit on the surface of the plants' root which directly obstruct the uptake of water and nutrients [28, 29]. Usage of nZVI also produces a by-product of $\mathrm{FeO}(\mathrm{OH})$ which studies have shown to damage DNA of the cell and cause peroxidation of lipids [30].

A lot of negative impacts of nZVI were observed from the research. Nevertheless, it is important to note that for most of the negative impact discussed, nZVI has a toxicity level way beneath other nano particles which may be due to the fact that iron itself is a common element found in most organisms $[31,32]$. 


\section{DISCUSSION}

There are plenty of methods to synthesize and produce nano zero valent iron (nZVI) based on studies from over all the years, which chemical reduction being the most practiced method for its simplicity and promising results. However, it does come with its cons such as requiring high cost and long time for production, harder to be manufactured in large scale without its consequences and so on. The introduction of a greener and more economical method of green synthesis aimed to solve the problem by using extracts from plants. With proper planning on how to obtain a sustainable source of plant either through employment of agro waste or other solutions, the method can become a real effective way of synthesizing nZVI at large scale, with less toll on the environment and at the same time more sustainable and economic. Therefore, development of green synthesis should be focused more in future studies to achieve the best procedures and parameters.

The study also reviewed the difference between traditional Fenton process and Sono-Fenton process where ultrasonic technology is introduced into the treatment via nZVI. Results have shown that SonoFenton process yields a much better result compared to Fenton process alone, and is also able to treat a wide range of pollutants, especially targeting recalcitrant organics which are difficult to be treated with traditional water treatment method. That being said, treatment of Sono-Fenton process on different types of pollutants requires very different parameters to achieve the best results. Hence, further studies on the treatment method should be made to obtain the ideal parameters of treating specific pollutants with maximum effectiveness and minimal resources.

Besides the production and application of nZVI for water remediation, it's possible impact on the environment has also been studied. From the journals reviewed, results have shown that nZVI definitely have its harmful effects on the environment including microorganisms, plants, cells and even human due to its toxicity. Because of these reasons, its usage on environmental remediation on a large scale are still doubted. Nevertheless, the toxicity level is already at the lowest if compared to most other nano particles. Therefore, rather than omitting the usage of nZVI for environmental remediation once and for all, further studies should be done to understand the toxicity of nZVI and possibly solutions to reduce the negative impacts.

\section{CONCLUSION}

It is undeniable that nano zero valent iron is the future of water or soil remediation due to its effectiveness, simplicity of synthesizing. Various methods of production have been discovered over the years, and should continue to be researched especially focussing on a greener, more economic and sustainable method such as green synthesis. In order to fully utilize the treatment method, further studies should also be carried out on its enhancement in treatment for maximum results, such as Sono-Fenton process discussed in the review. Even though studies have shown that the use of nZVI does come with its negative impact on the environment, it was also proven that the toxicity is actually at the lowest compared to other nano particles. Therefore, further research can be done to cope with the problem such as modifications of nZVI or better synthesizing methods.

\section{ACKNOWLEDGMENT}

The research is carried out with research grant provided by University College of Technology Sarawak (UCTS) research grant UCTS/RESEARCH/3/2018/08.

\section{REFERENCES}

[1] Li, L., et al., Nanoscale zero-valent metals: a review of synthesis, characterization, and applications to environmental remediation. Vol. 23. 2016.

[2] Taha, M.R. and A.H. Ibrahim, Characterization of nano zero-valent iron (nZVI) and its application in sono-Fenton process to remove COD in palm oil mill effluent. Journal of Environmental Chemical Engineering, 2014. 2(1): p. 1-8.

[3] Crane, R.A. and T.B. Scott, Nanoscale zero-valent iron: Future prospects for an emerging water treatment technology. Journal of Hazardous Materials, 2012. 211-212: p. 112-125.

[4] Stefaniuk, M., P. Oleszczuk, and Y.S. Ok, Review on nano zerovalent iron (nZVI): From synthesis to environmental applications. Chemical Engineering Journal, 2016. 287: p. 618-632.

[5] Shan, G., et al., Applications of Nanomaterials in Environmental Science and Engineering: Review. Vol. 13. 2009.

[6] Eljamal, R., et al., Improvement of the chemical synthesis efficiency of nano-scale zero-valent iron particles. Journal of Environmental Chemical Engineering, 2018. 6(4): p. 4727-4735.

[7] Wang, C.-B. and W.-x. Zhang, Synthesizing Nanoscale Iron Particles for Rapid and Complete Dechlorination TCE and PCBs. Vol. 31. 1997. 
[8] Tao, N.R., et al., Surface nanocrystallization of iron induced by ultrasonic shot peening. Nanostructured Materials, 1999. 11(4): p. 433-440.

[9] Jamei, M.R., M.R. Khosravi-Nikou, and B. Anvaripour, A novel ultrasound assisted method in synthesis of NZVI particles. 2013.

[10] Lim, J.-L. and M. Okada, Regeneration of granular activated carbon using ultrasound. Ultrasonics Sonochemistry, 2005. 12(4): p. 277-282.

[11] Schrick, B., et al., Hydrodechlorination of Trichloroethylene to Hydrocarbons Using Bimetallic Nickel-Iron Nanoparticles. Chemistry of Materials, 2002. 14(12): p. 5140-5147.

[12] Machado, S., et al., Green production of zerovalent iron nanoparticles using tree leaf extracts. Vol. 445-446C. 2013. 1-8.

[13] Machado, S., et al., Utilization of food industry wastes for the production of zero-valent iron nanoparticles. Vol. 496. 2014. 233-240.

[14] Hoag, G., et al., Degradation of bromothymol blue by 'greener' nano-scale zero-valent iron synthesized using tea polyphenols. Vol. 19. 2009. 8671-8677.

[15] Herlekar, M., S. Barve, and R. Kumar, Review Article Plant-Mediated Green Synthesis of Iron Nanoparticles. Vol. 2014. 2014.

[16] Machado, S., et al., Application of green zerovalent iron nanoparticles to the remediation of soils contaminated with ibuprofen. Science of The Total Environment, 2013. 461-462: p. 323-329.

[17] Gawande, S., An overview of the Fenton Process for Industrial Wastewater. 2015.

[18] Solarchem Environmental, S., The UV/oxidation handbook. 1994, Markham, Ont., Canada; Las Vegas, Nev.: Solarchem Environmental Systems.

[19] Zhang, J., et al., Application of Ultrasound and Fenton's Reaction Process for the Treatment of Oily Sludge. Procedia Environmental Sciences, 2013. 18: p. 686-693.

[20] Virkutyte, J., V. Vickackaite, and A. Padarauskas, Sono-oxidation of soils: Degradation of naphthalene by sono-Fenton-like process. Vol. 10. 2009. 526-536.

[21] Chakinala, A.G., et al., Treatment of industrial wastewater effluents using hydrodynamic cavitation and the advanced Fenton process. Ultrasonics Sonochemistry, 2008. 15(1): p. 49-54.

[22] Bremner, D.H., et al., Degradation of phenolic aqueous solutions by high frequency sono-Fenton systems (US-Fe2O3/SBA-15-H2O2). Applied Catalysis B: Environmental, 2009. 90(3): p. 380388.

[23] Auffan, M., et al., Relation between the Redox State of Iron Based Nanoparticles and Their Cytotoxicity toward Escherichia coli. Vol. 42. 2008. 6730-5.
[24] Xiu, Z.-m., et al., Effects of nano-scale zero-valent iron particles on a mixed culture dechlorinating trichloroethylene. Bioresource Technology, 2010. 101(4): p. 1141-1146.

[25] El-Temsah, Y.S. and E.J. Joner, Effects of nanosized zero-valent iron ( $\mathrm{nZVI}$ ) on DDT degradation in soil and its toxicity to collembola and ostracods. Chemosphere, 2013. 92(1): p. 131-137.

[26] Saccà, M.L., et al., Integrating classical and molecular approaches to evaluate the impact of nanosized zero-valent iron (nZVI) on soil organisms. Chemosphere, 2014. 104: p. 184-189.

[27] Tang, S. and I. Lo, Magnetic nanoparticles: Essential factors for sustainable environmental applications. Vol. 47. 2013.

[28] Yehia, E.-T. and E. Joner, Impact of Fe and Ag nanoparticles on seed germination and differences in bioavailability during exposure in aqueous suspension and soil. Vol. 27. 2012. 42-9.

[29] Ma, X., A. Gurung, and Y. Deng, Phytotoxicity and uptake of nanoscale zero-valent iron (nZVI) by two plant species. Vol. 443C. 2012. 844-849.

[30] Valko, M., H. Morris, and M.T. Cronin, Metals, toxicity and oxidative stress. Vol. 53. 2002. 13511365.

[31] Kharisov, B.I., et al., Iron-containing nanomaterials: synthesis, properties, and environmental applications. RSC Advances, 2012. 2(25): p. 9325-9358.

[32] El-Temsah, Y.S. and E.J. Joner, Ecotoxicological effects on earthworms of fresh and aged nano-sized zero-valent iron (nZVI) in soil. Chemosphere, 2012. 89(1): p. 76-82. 